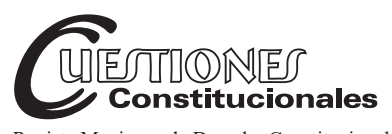

Revista Mexicana de Derecho Constitucional Núm. 39, julio-diciembre 2018

\title{
La eficacia de los derechos sociales en el siglo XX mexicano
}

\section{The Social Rights' Efficacy in the Mexican $20^{\mathrm{TH}}$ Century}

\section{Julio Eduardo SANCLIMENT MARTínEZ*}

Resumen: En México, los derechos sociales han tenido diversas naturalezas jurídicas desde su aparición en el texto constitucional de Querétaro. Así las cosas, mientras el entendimiento de éstos no representó mayor problema - sobre todo económicopara el gobierno - ya que pareciera que no se les considerara derechos subjetivos de las personas-, el Constituyente estuvo en posibilidad de adicionar diversas cláusulas sociales buscando fundamentalmente la legitimación del poder público. El entender el desarrollo de la naturaleza jurídica de los derechos sociales en México, resulta imprescindible para abordar el "cambio de paradigma" regido por una visión totalmente normativa que trajo la reforma de junio de 2011.

Palabras clave: Constitución, derechos sociales, siglo XX, eficacia, derecho subjetivo, norma programática.
ABSTRACT: In Mexico, Social Rights have had different legal natures since its inclusion in the Constitution of Querétaro. Moreover, the understanding of the Social Rights did not represent a major problem - especially economic - for Mexican Government, because those clauses were not considered as personal rights. Thus, the Constituent was able to add several social clauses seeking fundamentally the Government's legitimization. Understanding the development of Social Rights' legal nature is crucial to comprehend the "paradigm shift" (a totally normative vision of the Constitution) brought in 2011 by the Constitutional Amendment.

Keywords: Constitution, Social Rights, 20th Century, Normative Efficacy, Personal Right, Programmatic Norm.

* Profesor de Derecho constitucional en la Universidad Panamericana. Abogado por la Escuela Libre de Derecho y maestro en derecho constitucional por el Centro de Estudios Políticos y Constitucionales de Madrid.sancliment9@hotmail.com. 
Sumario: I. Introducción. II. Precisiones terminológicas. III. Concepto y naturaleza jurídica. IV. Características de los derechos sociales. Una especial referencia a su eficacia. V. Evolución en el constitucionalismo mexicano. VI. Conclusiones. VII. Bibliografía.

\section{INTRODUCCIÓN}

La nación mexicana ha sido objeto de diversos cambios en su manera de entender la política y sobre todo el derecho. Así las cosas, para entender el impacto que ha generado en el país el posible cambio de paradigma o concepción en materia de derechos humanos a raíz de la reforma de junio de 2011, es necesario entender el tipo de sistema jurídico político que se detenta. Para ello, una revisión desde el punto de vista histórico resulta pertinente y por demás útil.

Para entender la actualidad mexicana es necesario partir de las tesis contractualistas que dieron origen a la creación del Estado civil. En tal sentido, cobran relevancia pensadores como el célebre Locke y el ilustre oriundo de Ginebra, Rousseau. Así, y de manera genérica, la democracia y el liberalismo político serían los antecedentes de la forma de gobierno actualmente denominada "constitucionalismo democrático", y que subyace en cierta medida en el pensamiento del Constituyente revolucionario de Querétaro. Asimismo, es importante precisar que la Constitución de 1917 — derivado de la tradición monárquica que deviene de la época virreinalconsagró una estructura de tintes conservadores: fuerte en lo tocante al Ejecutivo; ello, sin perjuicio de que buscó una limitación al poder público con claros tintes liberales. Estos límites al poder fueron trazados al estilo del famoso artículo 16 de la Declaración de los Derechos del Hombre y del Ciudadano francesa, mediante una división del poder y un catálogo de derechos fundamentales. Aunado a esto, derivado de diversas circunstancias como la desigualdad que se vivía durante el mandato del presidente Porfirio Díaz, en la redacción de la carta magna de 1917 — que como se dijo, seguía una herencia liberal-conservadora - se injertaron cláusulas de tinte social, como el derecho a la educación, los derechos laborales y el régimen de la propiedad consagrada en el artículo 27.

Así las cosas, nacería la Constitución de 1917 - y durante prácticamente todo el siglo $\mathrm{XX}$-, pareciera que los derechos humanos no representaron 
mayor problema para el partido hegemónico. Ello, toda vez que mientras las llamadas libertades —o derechos de libertad de las personas - consistían fundamentalmente ${ }^{1}$ en abstenciones estatales (por ejemplo, no entorpecer la libertad de tránsito de las personas o la libertad de asociación), las cláusulas sociales parecieran no haber sido entendidas como auténticos derechos subjetivos, de tal manera que no representaban presupuestariamente esfuerzo alguno por parte del régimen.

Con la llegada de diversas crisis de la legitimación del poder público mexicano fundamentalmente a raíz de los movimientos estudiantiles de 1968, pareciera que se empieza a utilizar la inclusión y/o ampliación diversas cláusulas — sobre todo de naturaleza social — como medio para acrecentar los niveles de aceptación gubernamental dentro de la propia sociedad mexicana. Lo anterior no generaría presuntamente mayor impacto, toda vez que se entendía la Constitución de una manera más descriptiva que axiológica, de tal manera que no era admitida como una norma jurídica enteramente aplicable. Por el contrario, la idea que en su mayoría se tenía de la Constitución, era la de un documento de carácter político que solamente organizaba al poder público a la vez que hacía un reparto competencial entre los diversos órdenes de gobierno existentes. Esta manera de entender la Constitución, más como una maquinaria política que como una norma jurídica directamente aplicable, pareciera ser que determinó la vida y desarrollo de las cláusulas sociales mexicanas. Esa forma de entender la Constitución pareciera tener un parteaguas con la llegada de la Reforma Constitucional de junio de 2011, toda vez que la propia Constitución empezaría a ser entendida como una norma jurídica aplicable en su totalidad. Esto, pareciera haber contribuido a concebir los derechos sociales de una manera distinta de como se había hecho durante parte del siglo XX.

El objeto del presente trabajo será analizar la eficacia de los derechos sociales en el siglo XX mexicano. En este sentido, el trabajo parte de la hipótesis de que las cláusulas sociales no representaron auténticos derechos subjetivos desde su aparición en 1917, y hasta antes de la reforma constitucional de junio de 2011. Así, ¿los derechos sociales vincularon en el siglo XX al Estado mexicano de tal forma que crearon una obligación plenamente exigible? Es decir, ¿durante el siglo XX tuvieron eficacia jurídica directa o indirecta? Planteada en estos términos, se tratará de verificar dicha hipótesis. Para ello, la presente investigación se abordará desde el

Aunque no exclusivamente. 
punto de vista de la historia constitucional mexicana, sin perjuicio de que pueda hacerse referencia a otras disciplinas, como la teoría constitucional o la filosofía del derecho. Desde la óptica del derecho constitucional mexicano, resulta relevante determinar si el Estado ha estado vinculado respecto de las cláusulas sociales y, en su caso, en qué medida lo estuvo durante el siglo XX. Lo anterior para dejar plenamente establecida su concepción durante el novecientos y así estar en posibilidad de determinar mediante futuros trabajos, los cambios apuntados por la reforma de junio de 2011 en materia de eficacia de derechos sociales.

\section{Precisiones terminOlÓGICAS}

En primer lugar, resulta necesario distinguir las categorías de derechos humanos, derechos fundamentales, principios rectores y garantías individuales. En lo tocante a los derechos humanos, se entienden como: "conjunto de facultades e instituciones que, en cada momento histórico, concretan exigencias de la dignidad, la libertad y la igualdad humanas". ${ }^{2}$ Contrastándolos con los derechos fundamentales, que son "aquellos derechos humanos garantizados por el ordenamiento jurídico positivo, en la mayor parte de los casos en su normativa constitucional, y que suelen gozar de una tutela reforzada". ${ }^{3}$ Así, desde el punto de vista teórico, se habla de derechos humanos cuando se está en el plano de la ética, concretamente, en demandas o solicitudes fundamentadas en la dignidad humana, que no han sido positivizadas en la Constitución, mientras que los derechos fundamentales son concebidos, precisamente, como la positivización constitucional de los derechos humanos. Al respecto, Carbonell señala que "podríamos decir que todos los derechos fundamentales son derechos humanos constitucionalizados". ${ }^{4}$

Sobre los principios rectores, Rubio Llorente señala que "son normas que asignan fines determinados a la acción estatal". ${ }^{5}$ Así, es importante aclarar que son mandatos dirigidos al poder público y a las personas, por

\footnotetext{
2 Pérez Luño, Antonio E., Los derechos fundamentales, Madrid, Tecnos, 1991, p. 46.

3 Ibidem, p. 47.

4 Carbonell, Miguel, Los derechos fundamentales en México, México, PorrúaCNDH-UNAM, 2012, p. 9.

5 Rubio Llorente, Francisco, La forma del poder. Estudios sobre la Constitución, Madrid, Centro de Estudios Políticos y Constitucionales, 1997, p. 60.
} 
ejemplo, en el caso de la eficacia de los derechos en las relaciones habidas entre particulares.

Ahora bien, la situación positiva en México resulta un tanto distinta de lo que se ha expuesto. En este sentido hay que distinguir dos grandes momentos al efecto: el primero, del 5 de febrero de 1917 al 10 de junio de 2011; y el segundo, del 11 de junio de 2011 a la fecha. Durante todo el primer momento, la Constitución no se refería a las categorías en cuestión como derechos humanos o fundamentales; simplemente, al estilo hobbesiano, señalaba que el Estado otorgaba garantías individuales. Con la llegada del segundo momento, el Constituyente optó por una postura más rousseauniana, reconociendo ahora derechos humanos. Por lo anterior, podría decirse que, para el Constituyente mexicano, desde el punto de vista positivo, los derechos fundamentales son lo mismo que los derechos humanos.

\section{CONCEPTO Y NATURALEZA JURÍDICA}

Lo primero que debe señalarse sobre la categoría derechos sociales es que se trata de un término equívoco. Siguiendo a Salazar Ugarte, hay que distinguir que los derechos sociales no promueven un tipo especial de libertad, sino que buscan una igualdad específica que es distinta de la del liberalismo que implica igualdad formal; así, lo que busca el socialismo, corriente que los enmarca, es la igualdad material. En dicho sentido, las manifestaciones socialistas tienden a señalar que el desarrollo colectivo implica precondiciones sociales; es decir, la "superioridad del hombre asociado sobre el hombre aislado". ${ }^{6}$ Así, para poder hacerlos eficaces "requieren de un cierto modelo de organización estatal... que permita reconocer el deber moral de hacernos cargo de las necesidades de los demás": 7 el Estado social. Lo anterior implica una nueva participación del Estado mismo dentro de la vida de las personas, a diferencia del liberalismo donde debía

\footnotetext{
6 Salazar Ugarte, Pedro, La democracia constitucional. Una radiografía teórica, México, Fondo de Cultura Económina-UNAM, Instituto de Investigaciones Jurídicas, 2013, p. 150.

7 Carbonell, Miguel y Ferrer Mac-Gregor, Eduardo, Los derechos sociales y su justiciabilidad directa, México, Flores Editor y Distribuidor-UNAM, Instituto de Investigaciones Jurídicas, 2014, p. 2.
} 
inmiscuirse lo menos posible, aquí será uno de los principales promotores de los derechos sociales.

Para poder formular un concepto dentro de la presente investigación, se tomará el ensayo de Thomas Humphrey Marshall, ${ }^{8}$ ya que es una de las clasificaciones que más se ha utilizado para explicar la evolución de los derechos humanos, así como para delimitar características comunes entre ellos. Al respecto, distinguió tres elementos constitutivos de la ciudadanía: el civil, el político y el social. Es a partir de esta tesis que los derechos se clasificaron en distintas generaciones según su orden de aparición; con el elemento social, se refirió a un conjunto de posibilidades personales que comprendía: a) un nivel mínimo de estado de seguridad; b) un adecuado bienestar económico, y c) el poder vivir como un individuo civilizado de conformidad con los estándares dominantes en el lugar. ${ }^{9}$

Considerando los elementos desarrollados, para efectos del presente trabajo, se entiende por derecho social: Todo derecho humano contenido en el ordenamiento supremo mexicano, tendente a obtener la igualdad material, un nivel mínimo de seguridad y bienestar físico, sicológico y económico, y respecto del cual, se encuentran vinculados jurídicamente, tanto el poder público como las personas, mediante un dar, hacer o no hacer.

Pasando a otro punto, es necesario determinar la naturaleza jurídica de los derechos sociales. Para ello es importante comenzar con lo siguiente: en México, se encuentran positivizados en el orden jurídico supremo, que a raíz de la reforma de 2011, éste lo conforman —en materia de derechos humanos- la Constitución y los tratados internacionales. En este sentido, la única distinción entre derechos humanos será su fuente de reconocimiento, ya que en términos de la interpretación del artículo 1o. constitucional, prevalecerá la norma o interpretación más favorable, salvo restricción expresa contenida en la propia Constitución. ${ }^{10}$

8 Cfr. Humphrey Marshall, Thomas, "Ciudadanía y clase social”, trad. de Ma. Teresa Casado y Francisco Javier Noya Miranda, Revista Española de Investigaciones Sociológicas, núm. 79, 1950, pp. 297-344.

9 Cfr. Morales, Leticia, Derechos sociales constitucionales y democracia, Madrid, Marcial Pons, 2015, pp. 61-63.

10 “Artículo 1o. En los Estados Unidos Mexicanos todas las personas gozarán de los derechos humanos reconocidos en esta Constitución y en los tratados internacionales... Las normas relativas a los derechos humanos se interpretarán de conformidad con esta Constitución y con los tratados internacionales de la materia favoreciendo en todo tiempo 
En el derecho constitucional, es posible distinguir al menos dos visiones de las Constituciones: la política y la jurídica. Como norma jurídica, a su vez, puede verse como enteramente aplicable y también parcialmente aplicable. Es decir, con eficacia normativa directa o indirecta. En sentido similar, para De Otto, la disyuntiva de determinar el tipo de eficacia "no tiene nada que ver con el carácter normativo o no de la Constitución, pues sólo puede plantearse si previamente se parte de que la Constitución es una norma". ${ }^{11}$ Hilando con lo anterior, podrían distinguirse cuatro tipos de normas materiales de las Constituciones: derechos fundamentales, garantías institucionales, mandatos al legislador y principios y fines del Estado. ${ }^{12}$ Cada una tendrá distinta eficacia dependiendo de la naturaleza jurídica.

Así las cosas, respecto de la naturaleza jurídica: la de los derechos fundamentales, es de derecho subjetivo; pero la de los principios rectores, es de normas programáticas. Por último, sobre los derechos humanos, hay que distinguir que, en cuanto género de los derechos fundamentales, no se predica naturaleza jurídica alguna toda vez que se encuentran en el plano ético; y en cuanto concepto utilizado por el Constituyente de 2011, la naturaleza es de derecho subjetivo; ello, toda vez que se ha mostrado que, en México a partir de 2011, el Constituyente identifica derechos humanos y derechos fundamentales como lo mismo. En el sentido apuntado, ambas naturalezas vinculan al Estado en cuanto son disposiciones constitucionales, pero solamente los derechos subjetivos (algunos) traen aparejada garantía jurisdiccional. Así, mientras que los derechos subjetivos producen un beneficio, consistente en un dar, hacer o no hacer - dejando abierta la posibilidad para un derecho de acción, que puede existir o no-, las normas programáticas no generan un derecho para la persona, sino que gran parte de la eficacia pasa por un acto unilateral del poder público. El poder público se encuentra vinculado, pero no frente a la persona, sino en virtud de algún tipo de norma constitucional.

De lo anteriormente expuesto, se sigue que la naturaleza jurídica de las normas constitucionales está íntimamente relacionada con la eficacia de éstas.

a las personas la protección más amplia”. Véase también: Resolución, Pleno, 293/2011 de 3 de septiembre de 2013.

11 Otto, Ignacio de, Derecho constitucional. Sistema de fuentes, Barcelona, Ariel, 1987, p. 76.

12 Véase Rubio Llorente, Francisco, La forma del poder..., cit., pp. 54-60. 
En México actualmente los derechos sociales están comprendidos fundamentalmente dentro de los derechos humanos. Al menos, hablando desde el punto de vista estrictamente positivo constitucional.

\section{CARACTERÍSTICAS DE LOS DERECHOS SOCIALES. UNA ESPECIAL REFERENCIA A SU EFICACIA}

Hay que distinguir dos posibilidades para la eficacia de los derechos sociales: eficacia directa e indirecta. La indirecta implica que tuvieran una naturaleza jurídica de norma programática, lo que vincula mediante mandato al poder público. La directa

significa - al menos en su forma pura - que los jueces, y en general todos los llamados a aplicar el derecho, habrán de tomar la norma constitucional como una premisa de su decisión, igual que cualquier otra norma, con las siguientes consecuencias: a) dado que la Constitución es norma superior, habrán de examinar con ella todas las leyes y cualesquiera normas para comprobar si son o no conformes con la norma constitucional; b) habrán de aplicar la norma constitucional para extraer de ella la solución del litigio o, en general, para configurar de un modo u otro una situación jurídica; c) habrán de interpretar todo el ordenamiento conforme a la Constitución. En otras palabras, si la Constitución tiene eficacia directa no será sólo norma sobre normas, sino norma aplicable, no será solo fuente sobre la producción, sino también fuente del derecho sin más. ${ }^{13}$

En ese sentido, la naturaleza jurídica de las cláusulas sociales estará íntimamente relacionada con la eficacia que deben tener en el orden jurídico mexicano. Para entender la naturaleza jurídica actual $-\mathrm{y}$ por tanto su eficacia - es pertinente realizar un estudio histórico evolutivo de las cláusulas; así estaremos en posibilidad de entender muchos de los razonamientos de los operadores jurídicos del siglo XX mexicano y estaremos igualmente en posibilidad de identificar los cambios derivados del 2011; todo ello respecto a los derechos sociales.

13 Otto, Ignacio de, Derecho constitucional..., cit., p. 76. 


\section{EVOLUCIÓN EN EL CONSTITUCIONALISMO MEXICANO}

Una vez analizada la naturaleza jurídica y la consecuente eficacia de los derechos sociales en general, es necesario identificar cuál ha sido su situación dentro del ordenamiento jurídico mexicano. A tal efecto, se propone la siguiente clasificación, utilizando como criterio los diferentes cambios constitucionales que se han producido en la materia, para determinar si es que ha existido modificación en cuanto a su naturaleza jurídica y por consiguiente a su eficacia o simplemente un aumento cuantitativo:

1. La primera etapa, desde la promulgación de la Constitución el 5 de febrero de 1917, hasta el 31 de diciembre de 1974, fecha en que se realiza la primera reforma del texto en la materia de derechos sociales;

2. La segunda, desde 1974, hasta la reforma constitucional de junio de 2011; y

3. La tercera, que comprende desde la mencionada reforma hasta nuestros días.

\section{La primera generación de derechos sociales en México}

En el marco de la primera década del siglo XX, México experimentó los efectos producidos por la revolución, que formalmente dio inicio con la convocatoria de Francisco I. Madero, a través del Plan de San Luis, que instaba al pueblo mexicano a levantarse en armas el 20 de noviembre de 1910, en contra del gobierno del general Porfirio Díaz. Posteriormente, el país se encontraría sumergido en una guerra y es justamente en medio del conflicto bélico donde fue gestada la Constitución; en ese contexto se promulgaría en el antiguo Teatro de la República, ubicado en el centro de la ciudad de Querétaro hacia 1917. ${ }^{14}$ Así, resulta trascendental precisar y

14 Para una mayor profundidad en el estudio de los antecedentes revolucionarios de la Constitución mexicana de 1917 en general, y de la incorporación de garantías sociales, en particular, véase Carpizo, Jorge, La Constitución Mexicana de 1917, México, Porrúa, 1995, pp. 1-46; Martínez Cázares, Germán, "Un siglo de mentiras”, Reforma, México, 5 de febrero de 2017, disponible en: http://www.reforma.com/aplicacioneslibre/articulo/ default.aspx $? \mathrm{id}=1038778 \mathrm{\&} \mathrm{md} 5=7 \mathrm{~b} 3650 \mathrm{e} 563 \mathrm{c} 788 \mathrm{fbb} 3 \mathrm{~b} 5 \mathrm{a} 88 \mathrm{~b} 37 \mathrm{c} 8373 \mathrm{~d} \& \mathrm{ta}=0 \mathrm{dfdbac} 1$ $1765226904 c 16 c b 9 a d 1 b 2 e f e \& l c m d 5=a d f 2 d 044 d 289 a 667808029 e 416 f 5286 f$ (consulta- 
apuntar el descontento social que se vivía en el país durante el mandato de Díaz, pues la desigualdad social despertó al México "bronco" y esas inquietudes sociales, que a la postre serían plasmadas en el texto constitucional de 1917, pasaron a ser las herederas de los ideales revolucionarios. El partido hegemónico, quien corporativizaría los ideales revolucionarios, gozaría durante buena parte del siglo XX de legitimación popular, por ser precisamente los garantes del cumplimiento de los propios ideales revolucionarios.

Asimismo, es de advertir como ha dicho Gargarella, la Constitución de 1917 se creó con base en

tres modelos constitucionales diferentes, a los que llamamos conservador, radical y liberal. El primero, como sabemos, puede ser definido por su combinación de elitismo político y perfeccionismo moral (el modelo que en América Latina significó poderes concentrados en el Ejecutivo e imposición religiosa); al modelo radical — en fuerte disputa con el anterior - lo podemos caracterizar como un modelo rousseauniano, que destaca por su mayoritarismo político; y del liberal — que pretendió intermediar entre los dos anteriores - podemos resaltar su defensa de un sistema político de equilibrios. ${ }^{15}$

En tal sentido, el radicalismo social fue introducido por el Constituyente queretano en la medida que introdujo cláusulas sociales. Es decir, la carta magna estaba compuesta por tres tendencias que no resultarían fáciles de armonizar. La Constitución mexicana fue la primera en incorporar enunciados de tinte social dentro de su texto, inclusive antes de la alemana de Weimar de 1919. Así, es posible decir que la educación gratuita, los derechos agrarios, ciertos límites económicos en cuanto a posibles monopolios, oligopolios y prácticas monopólicas y, por último, los de naturaleza laboral, fueron aquellos que se reconocieron primigeniamente. ${ }^{16}$

da el 31 de mayo de 2017). Este último, siguiendo una postura liberal, menciona que la Constitución mexicana "brota de una lógica de poder, no de un movimiento ciudadano con genuinas reivindicaciones sociales. Es una intentona - fallida - por avenir a los triunfadores del posporifirismo y del poshuertismo".

15 Gargarella, Roberto, La sala de máquinas de la Constitución, dos siglos de constitucionalismo en América Latina (1810-2010), Madrid, Katz Editores, 2014, p. 255.

16 En el mismo sentido Carpizo, Jorge, "Las garantías sociales en la Constitución mexicana se encuentran en tres grandes regímenes: a) el régimen educativo regulado por el artículo 3o.; b) el régimen patrimonial y agrario regulado por los artículos 27 y 28 , y c) el régimen laboral regulado por el artículo 123". Carpizo, Jorge, Estudios consti- 
En esta etapa, la naturaleza jurídica de estos enunciados sociales no implicaba fundamentalmente prestaciones a cargo del Estado, ya que lo que el propio Estado hacía era vigilar que las relaciones entre particulares no fueran leoninas. Así, Cossío Díaz apunta que la

importancia de estos derechos sociales, con excepción del acceso a la educación, recae en la limitación que se les imponía a ciertas personas que se consideraban poderosas socialmente, para que no dañaran a otros sujetos que se estimaban — probablemente, con muy buenas razones - menos poderosos. ${ }^{17}$

Así las cosas, no eran ni siquiera normas programáticas (podríamos decir que la excepción fue el derecho a la educación, que ciertamente implicaba prestaciones a cargo del Estado y por lo tanto una carga importante al erario). Recordemos que la tradición programática sería una de las principales herencias que la Constitución alemana de Weimar dejaría al mundo, pero hasta 1919. De esta manera, durante este primer momento el poder público mexicano nunca estuvo vinculado; es decir, no tenía eficacia mediata, ni mucho menos inmediata, al menos en los términos apuntados. En dicho sentido, el cumplimiento estatal se pudo haber dado, pero como concesión graciosa, como un acto amable de los generales ahora corporativizados y que eran herederos de la revolución. Es de advertir que, en el siglo XX, se le dio una notable relevancia a este aspecto, interpretando en muchas ocasiones en el sentido de que las cláusulas sociales tenían efectos solamente entre particulares, excluyéndole responsabilidad al poder público. Al respecto, Burgoa señaló:

(S)e advierte que determinadas clases sociales, colocadas en una deplorable situación económica, exigieron del Estado la adopción de ciertas medidas proteccionistas, de ciertos medios de tutela frente a la clase social poderosa.

tucionales, México, Porrúa, 1991, p. 487. Al respecto, también señala Cossío Díaz: “[E]ncontramos tres artículos enunciados en un texto único que podríamos calificar como sociales, con un criterio muy general, de la siguiente manera: primero, el derecho a tener educación gratuita; segundo, el derecho agrario que contenía el artículo 27 y; tercero, los derechos de los trabajadores contenidos en el artículo 123". Cossío Díaz, José Ramón, "Políticas públicas, exigibilidad y justiciabilidad de los derechos sociales", en Zúñiga Ortega, Alejandra Verónica y Córdoba del Valle, Enrique (dirs.), Chávez de Mayo, Ana Matilde y Arango Chontal, Julio César (coords.), Derechos sociales. Políticas públicas, exigibilidad, justiciabilidad, Pamplona, Thomson Reuters, Aranzadi, 2015, p. 26.

17 Cossío Díaz, José Ramón, ibidem, p. 26. 
Por ende... al establecerse las garantías sociales... se formó una relación de derecho entre los grupos sociales favorecidos o protegidos y aquellos frente a los que se implantó la tutela. En vista de esta circunstancia, los sujetos del vínculo jurídico en que se traducen las garantías sociales son, por un lado, las clases sociales carentes del poder económico o de los medios de producción y en general los grupos colocados en situación precaria, y por tanto, las castas poseedoras de la riqueza o situadas en bonancible posición económica... ${ }^{18}$

Resulta interesante que uno de los autores más reconocidos y autorizados en la materia, como es Ignacio Burgoa, haya circunscrito las relaciones derivadas de las cláusulas sociales, exclusivamente al ámbito de las relaciones entre particulares - aunque ciertamente en la cuestión económica, una parte era mucho más poderosa que la otra. Asimismo, es importante destacar que, conforme a la visión apuntada, se pueden inferir ciertas cosas: lo primero que resalta es el hecho de que el rol que tenía el Estado mexicano, en relación con los derechos sociales, se había traducido en funciones meramente de supervisión o, en el mejor de los casos, de órgano decisor respecto de alguna posible infracción. En segundo lugar, se puede ver que el Estado mexicano no estaba en realidad vinculado para con las personas a ningún dar, hacer o no hacer, sino que simplemente se ubicaba en una posición jerárquicamente superior que le permitía vigilar que los particulares no vulneraran el texto constitucional; en el caso concreto, por ejemplo, que el patrón no abusara de las condiciones laborales en detrimento del trabajador. En este sentido, Carbonell apunta que "el Estado estaría por encima de las clases sociales en disputa, pero no tendría directamente obligaciones que atender... más allá de su papel de vigilante". ${ }^{19}$ Así, no resultaría difícil inferir que, en caso de alguna infracción por parte del patrón en detrimento del trabajador, la acción que tendría el trabajador sería en contra del patrón y no en contra del poder público, quien se limitaría a verificar que no existiera un abuso y a emitir mandamientos dirigidos al patrón para que concluya y/o en su caso resarza la conducta lesiva. Asimismo, pudiera válidamente presumirse que al poder público no le representaría mayor erogación monetaria llevar a cabo esta actividad.

Al hablar de los enunciados sociales en particular - y en estricto orden de aparición dentro del articulado de la Constitución original—, nos en-

\footnotetext{
18 Burgoa, Ignacio, Las garantías individuales, México, Porrúa, 2002, pp. 704 y 706.

19 Carbonell, Miguel, Los derechos fundamentales..., cit., p. 817.
} 
contramos con el derecho a la educación gratuita, consagrado en el artículo $30 .{ }^{20} \mathrm{Si}$ bien, tanto los derechos sociales como las libertades entrañan obligaciones de dar, hacer o no hacer, la realidad es que por ese solo hecho, los derechos no pierden su esencia liberal o social según sea el caso; más bien comparten los efectos jurídicos. En la educación, esto toma una mayor relevancia ya que del texto constitucional se puede apreciar que tenía - y sigue teniendo - una naturaleza dual. Ello es así ya que, por un lado, en lo que respecta a la libertad de enseñanza, podía verse como un derecho liberal, mientras que, por el otro, tiene tintes eminentemente sociales ya que el poder público estaría vinculado a "construir y mantener el sistema educativo nacional" 21 para hacer progresar en este ámbito a la población. No obstante, el detenerme a analizar en específico estos aspectos de la educación, desviaría el objeto de estudio. Basta con apuntar que el mismo tiene un aspecto meramente social que en la época que me ocupa compartía la misma concepción con los demás derechos sociales a que me he referido. Una precisión muy importante respecto de este derecho es que desde el punto de vista estrictamente de su naturaleza jurídica, el mismo implica —además de vigilar-, que el Estado cuente con recursos financieros para dotarlos de efectividad que, en principio, parece haber sido mucho mayor que la que debiera destinarse para vigilar que las relaciones laborales o agrarias no fueran abusivas. Esto se puede decir así, ya que — sobre todo en contraposición con los derechos de tinte laboral- los temas de educación atañen en el ámbito eminentemente público y a cualquier persona que no tenga la educación mínima que se exija por un texto constitucional. En tal sentido, la educación pública y gratuita se apartaría de la idea apuntada por Burgoa, ya que resulta imposible circunscribirlo al ámbito de las relaciones entre particulares, pues por definición la deberá proporcionar de algún modo el gobierno, ya que si la proporciona un particular, se está ante la educación privada. Así, resulta factible establecer que su naturaleza se asemejaba al concepto weimariano de norma programática.

Por otra parte, la situación agraria representaba todo un reto para el Constituyente de 1916-1917, debido a que grandes extensiones de la tierra mexicana se encontraban en manos de unas pocas personas; una manifes-

20 "Artículo 3o. La enseñanza es libre; pero será laica la que se dé en los establecimientos oficiales de educación, lo mismo que la enseñanza primaria, elemental y superior que se imparta en los establecimientos particulares...".

21 Carbonell, Miguel, Los derechos fundamentales..., cit., p. 843. 
tación de lo anterior, es el hecho de que previo a la entrada en vigor de la Constitución de Querétaro, en el estado de Chihuahua — el que mayor extensión territorial tiene dentro de la república mexicana con casi doscientos cincuenta mil kilómetros cuadrados - "una treintena de hacendados... poseyeran la totalidad de las tierras cultivables" 22 de la entidad. Lo anterior, parece haber sido razón suficiente para que el Constituyente reconfigurase la propiedad privada mediante la incorporación de una función social. La propiedad había estado inspirada hasta ese entonces, exclusivamente en los principios romanos - dejando de lado cualquier inmersión externa dentro del núcleo del derecho fundamental- de ius utendi, fruendi y abutendi, siendo característica de este último poder disponer de la cosa, incluso al grado de abusar de ella o, dicho de otra manera, de destruirla sin buscar ningún beneficio, ni siquiera propio y mucho menos de la sociedad. La lógica del artículo 27 constitucional fue que "sin desconocer la propiedad privada (se) instituyó la propiedad social, sobre la base de ordenar un reparto de tierras en una forma más justa, disfrutadas por quienes no podían venderlas, rentarlas o regalarlas". ${ }^{23} \mathrm{O}$, dicho de otro modo, pareciera que había impactado el carácter social en el más liberal de los derechos fundamentales, la propiedad, limitando así algunos de sus aspectos en favor de los que menos bienes tenían:

Artículo 27. ...La nación tendrá en todo tiempo el derecho de imponer a la propiedad privada las modalidades que dicte el interés público, así como el de regular el aprovechamiento de los elementos naturales susceptibles de apropiación, para hacer una distribución equitativa de la riqueza pública y para cuidar de su conservación...

Pasando a la cuestión económica, ésta tuvo un importante cambio cuando también se limitó fuertemente el mercado a través del artículo 28 de la Constitución. ${ }^{24}$ Es importante apuntar que, con base en este artículo, podría pensarse que el control que pretendía ejercer la carta magna, más que

22 Castro y Castro, Juventino V., "Los derechos sociales en la Constitución de 1917", en Ferrer Mac-Gregor, Eduardo y Zaldívar Lelo de Larrea, Arturo (coords.), La ciencia del derecho procesal constitucional. Estudios en homenaje a Héctor Fix-Zamudio en sus cincuenta años como investigador del derecho, México, UNAM, Instituto de Investigaciones Jurídicas, IMDPC y Marcial Pons, 2008, t. IV: Derechos fundamentales y tutela constitucional, p. 667.

23 Idem.

24 “Artículo 28. En los Estados Unidos Mexicanos no habrá monopolios ni estancos 
de tipo social, era de naturaleza eminentemente económica. No obstante que no haya sido una "conquista" estrictamente social, he decidido traerlo a colación. En ese sentido, la ratio iuris que subyacía en el precepto, parece haber sido que la totalidad de la población pudiera acceder a la compra de los artículos de primera necesidad. Así, para el Constituyente queretano, el dejar totalmente abierto el mercado para que se regulara por la ley de la oferta y la demanda, podría haber implicado un severo riesgo en materia de control de precios y acaparamientos de mercado. No obstante, la Constitución de 1917 seguía manteniendo el derecho de las personas para ejercer libremente el comercio y la industria, apartándose así de tendencias comunistas de apropiación estatal de los medios productivos. ${ }^{25}$

Respecto de los derechos laborales, con la aparición del artículo $123^{26}$ que contenía una amplísima regulación de las relaciones entre el patrón y el trabajador, se terminó con una tradición que subyace al derecho laboral; es decir, se rompió con la postura liberal que en la materia postulaba la Constitución de 1857. En consecuencia, ya no se regirían más las relaciones obrero-patronales exclusivamente por el principio pacta sunt servanda, sino que ahora se atendería a la equidad y correspondencia de los derechos y obligaciones de una y otra parte en el contrato. ${ }^{27}$

A la luz de lo anteriormente expuesto, se observa que el papel del Estado mexicano en estos derechos era principalmente el de una especie de árbitro que vigilaba por el cumplimiento. Realmente la disponibilidad de recursos financieros para la satisfacción pareciera haber sido mínima, comparada con la que le representaría en caso de que hablásemos de derechos prestacionales. Igualmente apunta Cossío Díaz, "salvo por la existencia de inspectores del trabajo, o del Departamento Agrario, que posteriormente fue la Secretaría de la Reforma Agraria". ${ }^{28}$ Así, el gobierno empezó a producir un discurso político comprometido con los derechos sociales. Además, a través del amparo, se encontró un medio indirecto para la protección de

de ninguna clase; ni exención de impuestos; ni prohibiciones a título de protección a la industria...".

25 Cfr. Castro y Castro, Juventino V., "Los derechos sociales en la...", cit., p. 667.

26 "Artículo 123. El Congreso de la Unión y las legislaturas de los estados deberán expedir leyes sobre el trabajo, fundadas en las necesidades de cada región; sin contravenir a las bases siguientes, las cuales regirán el trabajo de los obreros, jornaleros, empleados, domésticos y artesanos, y de una manera general todo contrato de trabajo...".

27 Cfr. Castro y Castro, Juventino V., op. cit., nota 23, p. 666.

28 Cossío Díaz, José Ramón, “Los derechos sociales en la...”, cit., p. 26. 
estos derechos; indirecto, ya que la reclamación era contra el particular, y en caso de que la justicia ordinaria no protegiera el derecho en cuestión, se acudía a la justicia federal para solicitarle la protección, produciendo el efecto de que se corrigiera esta situación mediante un nuevo mandamiento judicial, lo que indirectamente ataca la conducta primigenia que vulneró el derecho social.

Si estuviéramos ante otro tipo de derechos sociales, donde el Estado no funge como un supervisor de la constitucionalidad de los actos, sino que la plena satisfacción de los derechos implica una gran erogación de recursos, es presumible que el Estado mexicano hubiera adoptado una postura distinta respecto de los derechos sociales; menos promotora.

De lo expuesto se sigue que, en esta etapa, la regla fue concebir los derechos sociales como enunciados constitucionales que operaban entre particulares, donde el Poder Judicial vigilaba indirectamente que se cumplieran, a través del análisis de la legalidad de los actos. En este sentido, es posible presumir que no exigía disposición de recursos al Estado. Situación distinta es la que ocurrió con el derecho a la educación que implicó desde la primera etapa, principalmente, prestaciones a cargo del Estado. Así, su satisfacción dependió de modo prioritario de los recursos disponibles y de la voluntad gubernamental: al respecto, Carbonell apunta:

Hay en este contexto, dos tipos de aproximaciones, que son las que se han impuesto en el pasado... (p)ara la primera de ellas, los derechos sociales tendrían por objeto regular las relaciones jurídicas entre dos clases sociales... La segunda aproximación a la que se tiene que hacer referencia es la que entiende que los derechos sociales son mandatos de carácter programático. ${ }^{29}$

Esto se mantendría así hasta la presidencia de Luis Echeverría, donde se daría un giro a la izquierda en materia política.

\section{La segunda oleada y la concepción programática de los derechos sociales}

Con la llegada del sexenio de Echeverría (1970-1976), el país se vio inmiscuido en una nueva oleada de derechos sociales, misma que comenzó a gestarse con la primera reforma del artículo 4o. constitucional, de 31 de diciembre de 1974. Tras la reforma del artículo 4o., hay dos cuestio-

\footnotetext{
29 Carbonell, Miguel, Los derechos fundamentales..., cit., pp. 816 y 817.
} 
nes que merecen ser analizadas: a) el incremento cuantitativo de derechos sociales, y b) el cambio de la naturaleza jurídica de los mismos. Veamos detenidamente estos dos aspectos.

Sobre el aumento de la cantidad de derechos sociales, es importante apuntar que derivado de los acontecimientos en los cuales elementos militares y paramilitares sostuvieron enfrentamientos con la sociedad civil durante finales de los sesenta y principios de los setenta, el gobierno mexicano tuvo una disminución de legitimación. Por lo cual, a manera de análisis valorativo, el gobierno eminentemente priista debía tomar acciones tendentes a recuperar la estima del electorado de cara a las siguientes elecciones de 1976. Asimismo, no resulta inverosímil pensar que una manera de recuperar la legitimación sería la de dotar de mayor contenido social al pacto federal. Pareciera ser que en aras de recuperar la legitimación que había detentado el gobierno priista desde el final de la revolución, los derechos sociales se volvieron estandartes políticos y su inclusión en la Constitución resultaba por demás pertinente.

Esta proliferación de nuevos derechos sociales se desprende de las sucesivas reformas del artículo 4o.; derechos que se fueron añadiendo y que se tratarán de forma individualizada a continuación. En su redacción original, dicho precepto disponía lo siguiente:

Artículo 4o. A ninguna persona podrá impedirse que se dedique a la profesión, industria, comercio o trabajo que le acomode, siendo lícitos. El ejercicio de esta libertad sólo podrá vedarse por determinación judicial, cuando se ataquen los derechos de tercero o por resolución gubernativa, dictada en los términos que marque la ley, cuando se ofendan los derechos de la sociedad. Nadie puede ser privado del producto de su trabajo, sino por resolución judicial. La ley determinará en cada Estado cuáles son las profesiones que necesitan título para su ejercicio, las condiciones que deban llenarse para obtenerlo, y las autoridades que han de expedirlo.

Como se puede observar, su contenido esencial giraba en torno a la libertad para dedicarse a una determinada actividad, así como algunos lineamientos para desarrollarla. En ese sentido, se aprecia hasta cierto punto, una ausencia de identidad social dentro del precepto; es a partir de la mencionada reforma de 1974 que esa situación cambiaría: "Artículo 4o. (la ley) protegerá la organización y el desarrollo de la familia...". 
Según se ve, hay una primera tendencia de carácter social hacia la protección y desarrollo de la familia. Sin duda una modificación de tintes sociales, aunque hasta ese momento, este cambio no representaba una modificación significativa, desde el punto de vista de la vinculación del poder público para con las personas.

El 18 de marzo de 1980, se adicionó lo siguiente: “Artículo 4o... Es deber de los padres preservar el derecho de los menores a la satisfacción de sus necesidades y a la salud física y mental. La Ley determinará los apoyos a la protección de los menores, a cargo de las instituciones públicas".

Con esta adición, empieza a haber una tendencia muy marcada hacia la protección del interés superior de los menores; asimismo, le impone deberes tanto a los padres como al legislador democrático, quien deberá detallar los apoyos — se infiere que son vinculaciones de dar y/o hacerque las instituciones públicas deberán dar a los menores para garantizar su desarrollo. Un primer cambio se aprecia con esta adición. El Constituyente mexicano decidió expresamente vincular al legislador para la satisfacción de esta disposición de carácter social. Es de advertir que este párrafo fue modificado posteriormente en dos ocasiones más, la primera el 7 de abril del año 2000 y la segunda, el 12 de octubre de 2011.

E1 3 de febrero de 1983, se adicionó lo que sigue:

Artículo 4o... Toda persona tiene derecho a la protección de la salud. La ley definirá las bases y modalidades para el acceso a los servicios de salud y establecerá la concurrencia de la Federación y las entidades federativas en materia de salubridad general, conforme a lo que dispone la fracción XVI del artículo 73 de esta Constitución.

En esta primera reforma de 1983, llevada a cabo por el Constituyente, se introdujo uno de los derechos sociales por antonomasia: el derecho a la salud. Asimismo, el Constituyente indicó que era una materia concurrente, es decir, que tanto la Federación como las entidades tendrían facultades sobre la materia, pero cada una en distintos aspectos o ámbitos, sin llegar a ser coincidentes. A destacar resulta el hecho de que el Constituyente establece en una hipótesis normativa distinta, claro, dentro de mismo párrafo, la manera en la cual se llevará a cabo la satisfacción del derecho.

Asimismo, hubo otra reforma en 1983: “Artículo 4o... Toda familia tiene derecho a disfrutar de vivienda digna y decorosa. La ley establecerá los instrumentos y apoyos necesarios a fin de alcanzar tal objetivo". 
Uno de los típicos derechos sociales, el derecho a disfrutar de una vivienda digna y decorosa fue introducido mediante esta adición. Igualmente, el Constituyente impuso un mandato, al Legislativo. Similar al anterior, pareciera haber impuesto prioritariamente, vinculaciones jurídicas de $h a$ cer y de dar al poder público mexicano.

E1 28 de junio de 1999, se adicionó un párrafo que contenía el derecho a un medio ambiente adecuado para el desarrollo y bienestar. En ese momento, el Constituyente decidió no vincular expresamente al legislador, separándose - al menos expresamente - de lo que había venido realizando en las reformas constitucionales precedentes. En 2012, se volvió a cambiar la redacción del mencionado párrafo, un tanto en el mismo sentido de la vinculación legislativa, siguiendo la lógica de redacción seguida en las reformas anteriores de derechos sociales. El párrafo modificado es del tenor literal siguiente: "Artículo 4o... Toda persona tiene derecho a un medio ambiente sano para su desarrollo y bienestar. El Estado garantizará el respeto a este derecho. El daño y deterioro ambiental generará responsabilidad para quien lo provoque en términos de lo dispuesto por la ley".

Para el 30 de abril de 2009, el Constituyente adicionó otro párrafo; esta vez introdujo el derecho a la cultura, vinculando al Estado - no solamente al Poder Legislativo - respecto de la promoción, difusión y desarrollo cultural. Asimismo, le dirigió una orden al legislador, en el sentido de que será a través de la ley por donde se establezcan los mecanismos de acceso y participación en el ámbito cultural:

Toda persona tiene derecho al acceso a la cultura y al disfrute de los bienes y servicios que presta el Estado en la materia, así como el ejercicio de sus derechos culturales. El Estado promoverá los medios para la difusión y desarrollo de la cultura, atendiendo a la diversidad cultural en todas sus manifestaciones y expresiones con pleno respeto a la libertad creativa. La ley establecerá los mecanismos para el acceso y participación a cualquier manifestación cultural.

Es de advertir que el 13 de octubre de 2009, se consagró el derecho de las personas a una alimentación nutritiva, suficiente y de calidad; atribuyéndole al Estado mexicano la satisfacción del derecho constitucional en cuestión: "Artículo 4o... Toda persona tiene derecho a la alimentación nutritiva, suficiente y de calidad. El Estado lo garantizará". 
El derecho al agua suficiente y potable se adicionó el 8 de febrero de 2012 atribuyéndole una vez más la obligación de garantizar al Estado mexicano en su conjunto, pero atribuyéndole al legislador la definición de las bases, apoyos y modalidades encaminadas para dicho fin: "Artículo 4o... Toda persona tiene derecho al acceso, disposición y saneamiento de agua para consumo personal y doméstico en forma suficiente, salubre, aceptable y asequible. El Estado garantizará este derecho y la ley definirá las bases...".

El derecho a la cultura física y al deporte, así como el derecho a la identidad y a ser registrado ante el Registro Civil de la localidad, fueron adicionados al artículo 4o. el 12 de octubre de 2011 y el 17 de junio de 2014, respectivamente:

Artículo 4o...Toda persona tiene derecho a la identidad y a ser registrado de manera inmediata a su nacimiento. El Estado garantizará el cumplimiento de estos derechos. La autoridad competente expedirá gratuitamente la primera copia certificada del acta de registro de nacimiento... Toda persona tiene derecho a la cultura física y a la práctica del deporte. Corresponde al Estado su promoción, fomento y estímulo conforme a las leyes en la materia.

Conforme a lo expuesto anteriormente, el artículo 4o. de la Constitución mexicana se encuentra actualmente con una cantidad importante de derechos sociales y se puede apreciar una tendencia hacia el establecimiento de prestaciones para satisfacerlos. No obstante - como ya se mencionó anteriormente-, no es el único lugar donde se encuentran regulados los derechos sociales del sistema mexicano; por tanto, ante esta dispersión de disposiciones, para una correcta comprensión, será necesario realizar una interpretación sistemática de la Constitución.

Con la aparición de derechos sociales dotados de una carga vinculativa para el Estado mexicano con contenido prioritario de dar y/o hacer, la naturaleza jurídica se modificó para quedar como normas programáticas. Es de advertir que este cambio de concepción de la naturaleza jurídica no fue dado por alguien en particular, sino que fue derivado de la propia naturaleza de los cambios constitucionales apuntados. Así, mientras que en la primera etapa las cláusulas sociales se circunscribían a relaciones desiguales habidas entre particulares (como se ha dicho, excepto el derecho a la educación), en esta segunda etapa la propia esencia de los derechos incluidos y las modificaciones de los ya existentes, parecieran ser tendentes a 
contener conductas positivas para satisfacerlos. En ese orden de ideas, antes, las cláusulas sociales prácticamente no demandaban prestación alguna para el Estado, mientras que a raíz de la crisis de legitimación a que me he referido, el Estado ahora debía prestar ciertas conductas para volverlos una realidad. A propósito, señala Cossío Díaz, que en

el momento en que aconteció la constitucionalización de los derechos sociales, la doctrina mexicana de aquel entonces - esto es, finales de los setenta y prácticamente a lo largo de los ochenta y noventa—, retomó aquella vieja categoría de los derechos o las normas programáticas. Esto en virtud de que la incorporación de esta segunda generación de derechos sociales significaba el otorgamiento de prestaciones materiales por parte del Estado para poder satisfacer el derecho mismo. ${ }^{30}$

En tal sentido, parecería razonable decir que la concepción programática, que ya implicaba en cierta medida a la educación, se extendió a algunos nuevos derechos que llegaron al artículo 4o. con el desarrollo de esta segunda etapa.

Por otra parte, esta concepción programática de los derechos sociales, que ha sido entendida como vinculación jurídica al poder público, pero dependiente del Poder Legislativo para desarrollar los programas, así como de la autoridad administrativa respecto de la ejecución, tiene como trasfondo un tema presupuestario y de capacidad administrativa. Pareciera que, en cuanto a temas de eficacia, ésta era indirecta. Lo anterior implicaba que los derechos sociales no fueran directamente exigibles, ya que "mientras las garantías individuales son exigibles por el gobernado en forma directa y ante su violación, se tiene el medio procesal idóneo para reivindicarla, que es el juicio de amparo, las garantías sociales lo son de eficacia indirecta". ${ }^{31}$ Así, claramente se distinguía entre libertades y derechos o cláusulas sociales.

Con lo anterior, un tema importante respecto del tipo de derechos que nos ocupa es el tratamiento que los tribunales les dieron. La manera en que se pronunciaron ayuda a evidenciar la idea que imperó en esta etapa, respecto de otro aspecto de la eficacia: la garantía jurisdiccional. Si bien,

30 Cossío Díaz, José Ramón, "Políticas públicas, exigibilidad...”, cit., p. 27; véase Carpizo, Jorge, Temas constitucionales, México, Porrúa, 2003, p. 21.

31 Rojas Caballero, Ariel, Las garantías individuales en México, México, Porrúa, 2002 , pp. 582 y 583. 
un derecho debe distinguirse de su garantía, no es menos cierto que en la medida que esté garantizado, la nación tendrá un mejor desarrollo social. En esta etapa, hemos visto que la naturaleza jurídica atribuida a los derechos sociales es la de enunciados de carácter programáticos. O sea que no existe un derecho subjetivo por parte del beneficiario de la respectiva disposición constitucional, sino que por el contrario el poder público está vinculado en la medida de sus posibilidades a elaborar y posteriormente llevar a cabo. Así las cosas, el Poder Judicial de la Federación solicitó como requisito de legitimación para acceder al amparo, el acreditamiento del interés jurídico (que, de acuerdo con la jurisprudencia de la Suprema Corte mexicana, se identificaba con la titularidad de un derecho subjetivo). Los derechos sociales no tenían garantía de amparo, puesto que no había legitimación para solicitar: "El interés jurídico, reputado como un derecho reconocido por la ley, no es sino lo que la doctrina jurídica conoce con el nombre de derecho subjetivo...". ${ }^{32}$

Al respecto, Zaldívar Lelo de Larrea señala que “(d)urante el siglo XX... salvo casos muy aislados... el Poder Judicial federal y particularmente la Suprema Corte restringieron el acceso al amparo al acreditamiento del interés jurídico como derecho subjetivo en su concepción más rígida". ${ }^{33}$ De lo anterior se desprende que sólo podía acceder al juicio de amparo, aquel que tuviera un interés jurídico y que, por consiguiente, tuviera un derecho subjetivo. Es decir, toda vez que un derecho social era una norma programática, y que para acceder al juicio de amparo se requería interés jurídico y que, de acuerdo con la jurisprudencia mostrada, eso era igual a un derecho subjetivo; por lo tanto, un derecho social no podía ser objeto de reclamo por la vía del amparo.

\section{El impacto del carácter normativo de la totalidad de la Constitución en la actual configuración jurídica de los derechos sociales}

Hasta el momento se ha mostrado que, durante gran parte del siglo XX, los derechos sociales fueron entendidos en México, bien como normas

32 Semanario Judicial de la Federación, Séptima Época, Apéndice 2000, t. VI, Común, P.R. SCJN, p. 81. "INTERÉS JURÍDiCo. INTERÉS SIMPLE y MERA FACULTAD. CuÁNDO EXISTEN".

33 Zaldívar Lelo de Larrea, Arturo, Hacia una nueva Ley de Amparo, México, UNAM, 2002, p. 43. 
programáticas, bien como normas vigentes en las relaciones inequitativas habidas entre particulares y sin vinculación del poder público. Sobre lo anterior, cobra relevancia la visión que se tuviera de la Constitución mexicana ya que, como se ha dicho, impacta en la eficacia, que será directa o indirecta, dependiendo de las circunstancias. En este sentido, pareciera que gran parte de - como apunta Gargarella — ${ }^{34}$ los derechos sociales, hayan sido vistos como "cláusulas dormidas", lo cual pasa, sí, por la forma en que se concibió la Constitución, pero ello deriva de cómo se entendió el derecho en general, durante gran parte del siglo XX mexicano.

Por lo anterior, lo primero es señalar que la concepción que plantea de cierto modo que el juez es la boca de la ley, imperaría en gran parte del siglo XX mexicano. Es decir, lo que estaría en el centro de los reflectores sería la ley y no la Constitución, ya que ésta no se entendía como totalmente normativa desde el punto de vista jurídico. Por tanto, no sería posible entender a la Constitución, como un "ordenamiento legal de rango superior"; en dicho sentido es que el derecho mexicano fue entendido durante muchos años.

$\mathrm{Al}$ respecto, es necesario precisar el alcance e implicaciones de las dos visiones de la Constitución: como máquina o como norma. ${ }^{35}$ Es importante aclarar dos cuestiones antes de continuar. Primero, que no son excluyentes una y otra de las visiones, sino que simplemente abordan el fenómeno constitucional desde una óptica distinta: por un lado, como máquina, desde la visión política, y por el otro como norma, desde la visión jurídica; y segundo, que la Constitución siempre será "una especie del género norma y una norma no obligatoria sería una contradictio in adjecto", ${ }^{36}$ por lo que, en cierto modo, ambas visiones entienden a la Constitución como norma. La diferencia estaría en que, desde el punto de vista de la norma obliga todo su contenido - ya sea directa o indirectamente-.

Ahora bien, la Constitución como máquina tiene como principales funciones la de ser el fundamento de la validez del ordenamiento jurídico, así

34 Véase Gargarella, Roberto, La sala de máquinas de..., cit., pp. 261-266.

35 Se utilizan estos conceptos de Michel Troper, ya que son por demás explícitos puesto que reproducen una idea gráfica en las personas respecto de la idea que se analiza en el presente capítulo. Troper, Michel, "La máquina y la norma. Dos modelos de Constitución", Doxa, núm. 22, 1989, pp. 330-347, disponible en: file:///C:/Users/Julio\%20 Sancliment/Downloads/la-maquina-y-la-norma-dos-modelos-de-constitucion\%20(2).pdf (consultada el 28 de abril de 2017).

36 Ibidem, p. 331. 
como distribuir el poder y establecer esferas competenciales. De todo lo anterior, se puede inferir que la ley y por lo tanto el legislador democrático tienen un papel sumamente trascendente para esta visión. En ese sentido, ni siquiera resulta "necesario pensar la Constitución como norma obligatoria, puesto que ésta constriñe efectivamente". ${ }^{37}$

La anterior visión encaja con las ideas sobre la evolución de los derechos sociales en México, que se expusieron en los apartados 1 y 2 del presente apartado, en el sentido de que válidamente podría decirse que en sus inicios, la Constitución mexicana siguió la lógica de pensamiento político-jurídico que implicaba, ante todo, un contrato social por el cual surgió el Estado y que, en su versión jurídica, se transformó en la Constitución, misma que fue el punto de partida del orden jurídico mexicano y que creó "órganos constituidos", siendo uno de ellos el Legislativo que, como se dijo, fue dotado de alta estima dentro del sistema y en donde el juez se limitaba a ser la boca muda de la ley. Es decir, se tenía un constitucionalismo descriptivo.

Para efectos del presente trabajo, lo relevante de la manera de ver las Constituciones, estriba en el impacto que una y otra óptica tuvieron dentro de la eficacia los derechos sociales. Así, la Constitución entendida como una norma jurídica, sea parcial, sea total, produce eficacia directa o indirecta según el caso. Estas ideas sobre la eficacia llegarían a México, fundamentalmente en la década de los ochenta. Desde la actualidad, es posible sostener que esta forma de entender la Constitución se ha ido modificando paulatinamente en México. Al respecto Cossío Díaz señala:

Estoy convencido de que no es ésta la causa generadora del cambio, ya que concurrieron muchos más elementos; pero cuando llega a México el título de un libro que aquí causó mucho revuelo, como también lo causó en España, el libro de don Eduardo García de Enterría, La Constitución como norma y el Tribunal Constitucional, se empezó a hacer click - por decirlo de manera pintoresca - en el sentido de que lo que teníamos era una Constitución como norma jurídica y, por tanto, tenía que satisfacer ciertas condiciones de validez. Sin duda alguna, aquí hubo un cambio cultural fundamental, pero ya fue hasta la primera parte de este siglo cuando comenzaron a hacer los ajustes necesarios. ${ }^{38}$

\footnotetext{
37 Ibidem, p. 336.

38 Cossío Díaz, José Ramón, "Políticas públicas, exigibilidad...”, cit., pp. 29 y 30.
} 
Así, con la llegada de los años noventa, la manera de entender la Constitución empezó a cambiar. En ese ambiente de inicio del cambio es que llegaría la reforma de derechos humanos de 2011. Al respecto, la reforma tuvo un impacto central en la eficacia de los derechos sociales, ya que al establecer mediante criterio orientativo que la Constitución es una norma jurídica, en los términos que lo hace, pareciera estar encaminado a reconocer plenamente la directa. Al efecto, la Primera Sala de la Suprema Corte de Justicia de la Nación ${ }^{39}$ distinguió que dicho carácter normativo, implica tres cosas: a) que todo el contenido de la Constitución tiene un valor normativo inmediato y directo; b) que la Constitución necesita valerse de un esquema apropiado que la proteja frente a actos o disposiciones que la pretendan vulnerar; y c) que la Constitución es el fundamento de validez del resto del ordenamiento jurídico, de lo cual se desprende la posibilidad de llevar a cabo un control de regularidad normativa respecto de aquellas disposiciones que la contraríen. Asimismo, es de advertir que el anterior, constituye un criterio aislado, por lo que no es de observancia obligatoria sino orientativa. Asimismo, para entender la visión de la Constitución, resulta importante atender al sentido de la interpretación de la Suprema Corte.

\section{CONCLUSIONES}

Al iniciar el presente trabajo de investigación, se partía de una intuición basada en que los derechos sociales no tenían en el México del siglo XX, la naturaleza de derechos subjetivos. Lo primero que hay que apuntar al respecto es que, desde el punto de vista teórico, fue posible identificar la naturaleza jurídica subjetiva con la eficacia directa y la naturaleza jurídica programática con la de principios rectores. La manera en que se entiende la Constitución en un Estado, determina de manera muy importante la eficacia de los derechos sociales. Sin embargo, lo que realmente hace que un derecho social sea eficaz directamente, es su naturaleza de derecho subjetivo.

39 Gaceta del Semanario Judicial de la Federación, Décima Época, primera sala, aislada, libro 17, abril de 2015, t. I, p. 485. Tesis 1a. CXXXV/2015, “Constitución. Su CONCEPCIÓN COMO NORMA JURÍDICA". 
Sobre el concepto de derechos humanos, derechos fundamentales, principios rectores y garantías individuales, existe una diversidad de entendimientos. En este sentido, dependiendo del tiempo y del lugar en el que se encuentre, es lo que cada uno va a significar — al menos desde el punto de vista positivo- . Desde el punto de vista teórico, a cada uno de los conceptos le corresponde una naturaleza jurídica distinta. No obstante, los diversos constituyentes — por ejemplo, el mexicano - cambian y utilizan de manera indistinta los términos; en tal sentido, pareciera que es prácticamente imposible llegar a un consenso. Lo anterior no es del todo cierto, ya que para estar en posibilidad de uniformar criterios, se debe abordar el punto desde la esencia y no desde la terminología usada. Así, por ejemplo, un derecho fundamental será siempre un derecho subjetivo positivizado en el ordenamiento supremo, no obstante que el Constituyente mexicano de 2011 le haya llamado derecho humano.

Sobre la naturaleza jurídica de los derechos sociales, se puede concluir que la misma va a cambiar dependiendo del lugar y sobre todo de la Constitución. Siguiendo la misma lógica de la conclusión anterior, esto es así, ya que la naturaleza de un derecho social no se tiene por el hecho de su contenido, sino por ser derecho subjetivo o norma programática, según sea el caso. Por ello, no es lo mismo el derecho subjetivo que la garantía; la eficacia directa deviene de la idea de derecho subjetivo y no de la capacidad que se tenga para cumplir lo obligado o responder ante un incumplimiento. Dicho de otro modo, la eficacia directa se encuentra en el plano del deber ser mientras que las garantías se encuentran en el ser.

Sobre la evolución de la eficacia de los derechos sociales en el ordenamiento jurídico mexicano, es posible concluir que, durante la primera etapa, no tenían valor vinculante frente al poder público. Eran concebidos más como "un buen deseo" que como una realidad; en gran parte por la asignación de éstos al campo de las relaciones habidas entre particulares. Es decir, no tenían eficacia normativa $-\mathrm{O}$ al menos, era extraordinariamente baja - puesto que la Constitución era entendida fundamentalmente desde la óptica de la máquina. En la segunda etapa, la naturaleza jurídica fue la de normas programáticas, lo que implicó un cambio paulatino en la manera de entender la Constitución, ya que podría decirse que empezaba a tener eficacia mediata. Ello, toda vez que, de la lectura de las reformas habidas en el siglo XX, se aprecia una gran cantidad de mandatos expresos. Así, el legislador es la figura central y el juez un autómata. 
Mientras no hubo problemas o crisis de legitimación estatal frente a los gobernados, el Estado mexicano no tuvo ningún problema; ello porque los derechos consagrados en el texto de 1917 no implicaban prestaciones (excepto la educación que siguió y sigue un régimen especial) de ningún tipo. El problema vendría con las crisis de la legitimación porque en aras de obtener mayores índices de aceptación, se comenzó a ampliar el catálogo de derechos sociales, sólo que ahora implicarían prestaciones por su propia naturaleza. Ante esta situación, el régimen homogéneo del poder optó por considerarles norma programática y de esta manera libraba un problema económico fuerte que ellos mismos se habían provocado.

Para el paso de una visión parcial a una visión totalmente normativa, inicialmente fue un cambio gradual. La doctrina jugó un papel importante en el comienzo del cambio de la concepción, misma que se adoptaría formalmente con la reforma de junio de 2011. El cambio de 2011, sin duda es un reto para los derechos sociales.

Hasta aquí se ha dejada apuntada la concepción que en México se tuvo de los derechos sociales durante el siglo XX. Ahora será necesario - tomando como base el presente trabajo - que se realice un análisis de la eficacia de los derechos sociales derivado de la reforma de 2011. Esa es una asignatura pendiente para el autor.

\section{BiBLIOGRAFÍA}

Abramovich, Víctor y Courtis, Christian, Los derechos sociales como derechos exigibles, Madrid, Trotta, 2002.

Alexy, Robert, Teoría de los derechos fundamentales, trad. de Ernesto Garzón Valdés, Madrid, Centro de Estudios Políticos y Constitucionales, 2000.

Aragón ReYes, Manuel, "El control como elemento inseparable del concepto de Constitución”, Revista Española de Derecho Constitucional, núm. 19, 1987.

BerLIN, Isaiah, Dos conceptos de libertad y otros escritos, España, Alianza, 2005.

BurgoA, Ignacio, Las garantías individuales, México, Porrúa, 2002.

BurGoA, Ignacio, Diccionario de derecho constitucional, garantías y amparo, México, Porrúa, 1984. 
Canosa Usera, Raúl, El control de convencionalidad, Navarra, Thomson Reuters-Aranzadi, 2015.

Carbonell, Miguel, Los derechos fundamentales en México, México, Porrúa-CNDH-UNAM, 2012.

Carbonell, Miguel y Ferrer Mac-Gregor, Eduardo, Los derechos sociales y su justiciabilidad directa, México, Flores Editor y DistribuidorFlores, 2014.

Cascajo Castro, José Luis, La tutela constitucional de los derechos sociales, Madrid, Centro de Estudios Constitucionales, 1988.

Castro y Castro, Juventino V., "Los derechos sociales en la Constitución de 1917", en Ferrer MAC-Gregor, Eduardo y ZALDívar Lelo DE LARREA, Arturo (coords.), La ciencia del derecho procesal constitucional. Estudios en homenaje a Héctor Fix-Zamudio en sus cincuenta años como investigador del derecho, derechos fundamentales y tutela constitucional, México, IMDPC-Marcial Pons-UNAM, Instituto de Investigaciones Jurídicas, 2008, t. IV.

CArpizo, Jorge, La Constitución mexicana de 1917, México, Porrúa, 1995.

CARPIZO, Jorge, Estudios constitucionales, México, Porrúa, 1991.

Carpizo, Jorge, Temas constitucionales, México, Porrúa, 2003.

Coaña Be, Luis David, Curso básico de amparo, México, Centro de Estudios Jurídicos Carbonell, 2017.

Cossío DíAz, José Ramón, "Evolución e involución de los derechos humanos en las sentencias de la Suprema Corte de Justicia", en Rubio LloRENTE, Francisco et al. (coords.), La Constitución política de España. Estudios en homenaje a Manuel Aragón Reyes, Madrid, Centro de Estudios Políticos y Constitucionales, 2016.

Cossío DíAz, José Ramón, "Políticas públicas, exigibilidad y justiciabilidad de los derechos sociales", en ZúÑIgA OrTEGA, Alejandra Verónica y Córdoba del Valle, Enrique (dirs.), Chávez de Mayo, Ana Matilde y Arango Chontal, Julio César (coords.), Derechos sociales. Politicas públicas, exigibilidad, justiciabilidad, Pamplona, Thomson Reuters-Aranzadi, 2015.

Cossío DíAz, José Ramón, El Estado social y derechos de prestación, Madrid, Centro de Estudios Constitucionales, 1989. 
Cossío Díaz, José Ramón et al., El caso Radilla. Estudio y documentos, México, Porrúa, 2012,

Cueva, Mario de la, Teoría de la Constitución, México, Porrúa, 1982.

Díez-Picazo, Luis María, Sistema de derechos fundamentales, Navarra, Thomson Reuters-Aranzadi, 2008.

Escobar Roca, Guillermo, Introducción a la teoría jurídica de los derechos humanos, Madrid, Trama Editorial, 2005.

EIDE, Absjorn, "Realización de los derechos económicos y sociales. Estrategia del nivel mínimo", Revista de la Comisión Internacional de Juristas, núm. 43, 1989.

Ferrajoli, Luigi, Derecho y razón, Madrid, Trotta, 2000.

Ferrajoli, Luigi, "Garantías", Revista Jueces para la Democracia, núm. 38, 2000, disponible en: file:///C:/Users/Julio\%20Sancliment/Down loads/Dialnet-Garantias-174825.pdf.

Ferrajoli, Luigi, Derechos y garantías, Madrid, Trotta, 2006.

Ferrajoli, Luigi, Derechos y garantías. La ley del más débil, Madrid, Trotta, 1999.

FiX-Zamudio, Héctor, "Breves reflexiones sobre el concepto y el contenido del derecho procesal constitucional", en Ferrer MAC-GreGOR, Eduardo (coord.), Derecho procesal constitucional, México, Porrúa, 2003.

FiX-Zamudio, Héctor, Estudio de la defensa de la Constitución en el ordenamiento mexicano, México, Porrúa, 2011.

García de EnTERría, Eduardo, La Constitución como norma y el Tribunal Constitucional, Navarra, Thomson Reuters-Aranzadi, 1981.

García MáYnez, Eduardo, Introducción al estudio del derecho, México, Porrúa, 2002.

Gargarella, Roberto, La sala de máquinas de la Constitución, dos siglos de constitucionalismo en América Latina (1810-2010), Madrid, Katz Editores, 2014.

GARZÓN VALDÉS, Ernesto, "Representación y democracia”, Doxa, núm.6, 1989.

Guastini, Ricardo, Distinguendo. Studi di teoría e metateoria del diritto, Turín, Giappichelli, 1996. 
Hohfeld, Wesley, “Conceptos jurídicos fundamentales”, Yale Law Journal, núm. 23, 1913, trad. de Genaro Carrió, México, Fontamara, 1991.

IGNATIEFF, Michael, Los derechos humanos como política e idolatría, Barcelona, Paidos, 2003.

JimÉNEZ CAMPO, Javier, Derechos fundamentales. Concepto y garantías, Madrid, Trotta, 1999.

JimENA QUESADA, Luis, La Europa social y democrática de derecho, Madrid, Dykinson, 1997.

Martínez CÁzARes, Germán, "Un siglo de mentiras", Reforma, México, 5 de febrero de 2017, disponible en: http://www.reforma.com.

Medina Mora F., Alejandra et al., Derechos humanos y restricciones. Los dilemas de la justicia, México, Porrúa, 2015.

Mujangos y GonzÁLEZ, Javier, Los derechos fundamentales en las relaciones entre particulares, México, Porrúa, 2007.

Morales, Leticia, Derechos sociales constitucionales y democracia, Madrid, Marcial Pons, 2015.

Pereira Menaut, Antonio-Carlos, Lecciones de teoría constitucional, México, Porrúa, 2005.

Pérez Luño, Antonio E., Los derechos fundamentales, Madrid, Tecnos, 1991.

PisAREllo, Gerardo, Los derechos sociales y sus garantías. Elementos para una reconstrucción, Madrid, Trotta, 2007.

Porrúa PÉREz, Francisco, Doctrina politica de las garantías individuales, México, Porrúa, 1961.

Quadra-Salcedo Janini, Tomás de la, "Los derechos sociales en la Unión Europea", en Отто, Ignacio de, Derecho constitucional. Sistema de fuentes, Barcelona, Ariel, 1987.

Rabasa, Emilio O., El pensamiento politico y social del Constituyente de 1916-1917, México, UNAM, 1996.

Radbruch, Gustav, "Filosofía del derecho", Revista de Derecho Privado, trad. de José Medina Echavarría, Madrid, 1933.

Requejo Rodríguez, Paloma (coord.), Derechos sociales. Cátedra de amparo de derechos y libertades, Oviedo, Universidad de Oviedo, 2012.

Rubio Llorente, Francisco, La forma del poder. Estudios sobre la Constitución, Madrid, Centro de Estudios Políticos y Constitucionales, 1997. 
Robles Morchón, Gregorio, Sobre el concepto de Constitución, Real Academia de Ciencias Morales y Políticas, 2016, disponible en: http:// www.racmyp.es/R/racmyp/docs/anales/A97/A97-5.pdf.

Rojas Caballero, Ariel, Las garantías individuales en México, México, Porrúa, 2002.

Salazar Ugarte, Pedro, La democracia constitucional. Una radiografia teórica, México, Fondo de Cultura Económica-UNAM, Instituto de Investigaciones Jurídicas, 2013.

Tena Ramírez, Felipe, Derecho constitucional mexicano, México, Porrúa, 1991.

Troper, Michel, "La máquina y la norma. Dos modelos de Constitución", Doxa, núm. 22, 1989, disponible en: file:///C:/Users/Julio\%20Sancli ment/Downloads/la-maquina-y-la-norma-dos-modelos-de-constitucion\%20(2).pdf.

Zagrebelsky, Gustavo, Principios y votos. El Tribunal Constitucional y la politica, Madrid, Trotta, 2008.

Zagrebelsky, Gustavo, Historia y Constitución, trad. de Miguel Carbonell, Madrid, Trotta, 2006.

Zaldívar Lelo de Larrea, Arturo, Hacia una nueva Ley de Amparo, México, UNAM, 2002.

Fecha de recepción: 8 de noviembre de 2017.

Fecha de dictamen: 22 de noviembre de 2017. 